\title{
Numerical analysis of Newtonian flows based on artificial compressibility $A C$ method
}

\author{
Bashaeer K. Jassim Alaa H. Al-Muslimawi \\ University of Basrah, College of Science, Department of Mathematics \\ Email: bashaeir90@yahoo.com
}

Recived : $28 \backslash 9 \backslash 2017$

Revised : 8\10\2017

Accepted : $16 \backslash 10 \backslash 2017$

\begin{abstract}
In this study, numerical analysis for incompressible Newtonian flows has been conducted by using an artificial compressible method ( $A C$-method) based on the Galerkin finite element approach. As well known, Naiver-Stoke partial differential equations are employed to describe activity of the fluid. This model, which consists of two differential equations; named the conservation of mass and timedependent conservation of momentum is presented in cylindrical coordinates system (Axisymmetric flow). The effects of many factors such as Reynolds number ( $R e$ ) and artificial compressibility parameter $\left(\beta_{a c}\right)$ are discussed in the present study. In particular, this study emphasized on the impact of these parameters on the level of convergence. To satisfy the analysis of the method, Poiseuille flow along a circular conduit under isothermal condition is utilized as a simple test problem. This test is conducted by taking a circular cross section of pipe.
\end{abstract}

Keywords: Finite Element Methods; Galerkin Method; Navier-Stokes; Artificial Compressibility Method; Newtonian Flow

Mathematics Subject Classification 2010 :35Q30, 65M60 


\section{Introduction}

The artificial compressibility $(A C)$ method represents the early methods introduced for solving the Navier-Stokes differential equations. As is well known, under the incompressibility condition at both inside and boundaries of domain, the pressure components can be computed by using Poisson equation when the velocity is given. To avoid the complicated which is coming from that pressure decoupling process, Chorin [1] improved this $A C$-method to solve the steady state incompressible Navier-Stokes differential equations. The basis of this scheme is adding an artificial time derivative to the continuity equation to transform the system of equations from elliptic incompressible system to a hyperbolic compressible system. $A C$-method is adopted by many authors to solve various problems of incompressible flow; see for example Steger and Kutler [2], Peyret and Taylor [3], Chang and Kwak [4], Choi and Merkle [5], Rizzi and Eriksson [6], Rogers et al. [7] and Temam [8].

Furthermore, this method extended successfully to solve unsteady problems. At the first Peyret [9] and Peyret and Taylor [3] are extended the $A C$-method to solve the Navier-Stokes equations in unsteady situation under incompressibility condition. In addition, the extension of this approach for unsteady problems has had extensive coverage in the literature ([10]-[18]). The method is also implemented to analysis other kinds of equations in steady state situation (see Madsen and Larsen [19]). Farmer et al [20] discussed the solution of the Euler equations by using the multi-grid method and $A C$-method in parallel for free surface situation. In addition, implementation of a geometric multi-grid method for the $A C$-method is investigated by Yuan [21] to solve viscous flow. Moreover, the exact Riemann flux is introduced for $A C$ method by Bassi et al.[22], who also provided the discontinuous Galerkin approach to solve steady incompressible flow problems.

In the present study, $A C$-method is implemented to solve the governing equations of incompressible Newtonian flow in cylindrical coordinates. The particular numerical scheme adopted based on a Galerkin finite element approach. Determining the critical levels of Reynolds number ( $R e$ ) is the main feature of this study. Moreover, the convergence rate of solution under the variation of artificial compressibility parameter and Reynolds number also investigated. 


\section{Mathematical modeling}

For isothermal flow of an incompressible fluid the balance conservation of mass is given by $\frac{1}{r} \frac{\partial r u_{r}}{\partial r}+\frac{1}{r} \frac{\partial u_{\theta}}{\partial \theta}+\frac{\partial u_{z}}{\partial z}=0$.

And the momentum equations in the cylindrical components are presented as

\section{$r$-component}

$$
\begin{aligned}
& \frac{\partial u_{r}}{\partial t}+u_{r} \frac{\partial u_{r}}{\partial r}+\frac{u_{\theta}}{r} \frac{\partial u_{r}}{\partial \theta}-\frac{u_{\theta}^{2}}{r}+u_{z} \frac{\partial u_{r}}{\partial z}= \\
& -\frac{1}{\rho} \frac{\partial p}{\partial r}+\frac{\mu_{s}}{\rho}\left(\frac{1}{r} \frac{\partial}{\partial r}\left(r \frac{\partial u_{r}}{\partial r}\right)-\frac{u_{r}}{r^{2}}\right. \\
& \left.+\frac{1}{r^{2}} \frac{\partial^{2} u_{r}}{\partial \theta^{2}}-\frac{2}{r^{2}} \frac{\partial u_{\theta}}{\partial \theta}+\frac{\partial^{2} u_{r}}{\partial z^{2}}\right),
\end{aligned}
$$

\section{$\theta$-component}

$\frac{\partial u_{\theta}}{\partial t}+u_{r} \frac{\partial u_{\theta}}{\partial r}+\frac{u_{\theta}}{r} \frac{\partial u_{\theta}}{\partial \theta}+\frac{u_{r} u_{\theta}}{r}+u_{z} \frac{\partial u_{\theta}}{\partial z}=$ $-\frac{1}{r \rho} \frac{\partial p}{\partial \theta}+\frac{\mu_{s}}{\rho}\left(\frac{1}{r} \frac{\partial}{\partial r}\left(r \frac{\partial u_{\theta}}{\partial r}\right)-\frac{u_{\theta}}{r^{2}}\right.$

$\left.+\frac{1}{r^{2}} \frac{\partial^{2} u_{\theta}}{\partial \theta^{2}}+\frac{2}{r^{2}} \frac{\partial u_{r}}{\partial \theta}+\frac{\partial^{2} u_{\theta}}{\partial z^{2}}\right)$,

\section{$z$-component}

$$
\begin{aligned}
& \frac{\partial u_{z}}{\partial t}+u_{r} \frac{\partial u_{z}}{\partial r}+\frac{u_{\theta}}{r} \frac{\partial u_{z}}{\partial \theta}+u_{z} \frac{\partial u_{z}}{\partial z}= \\
& -\frac{1}{\rho} \frac{\partial p}{\partial z}+\frac{\mu_{s}}{\rho}\left(\frac{1}{r} \frac{\partial}{\partial r}\left(r \frac{\partial u_{z}}{\partial r}\right)+\right. \\
& \left.\frac{1}{r^{2}} \frac{\partial^{2} u_{z}}{\partial \theta^{2}}+\frac{\partial^{2} u_{z}}{\partial z^{2}}\right) .
\end{aligned}
$$

Such that $u_{r}, u_{\theta}$ and $u_{z}$ represent the velocity in $r$-direction, $\theta$-direction and $z$ direction. Also, $p$ is the pressure, $\rho$ is the

(1density of the fluid and $\mu_{s}$ is the solvent viscosity. In contrast, the equation can be also defined by the non-dimensional groups of Reynolds number ( $R e$ ), and viscosity $(\beta)$, which are defined by the scales of velocity ( $U$ ), length ( $L)$ and density $(\rho)$ as, $\operatorname{Re}=\rho \frac{U l}{\mu_{s}}$ and $\beta=\mu_{s}$ (for more details see [23],[24]).

\section{Numerical scheme}

\subsection{Artificial compressibility method}

To solve the system of governing differential equations, the artificial compressibility method (AC-method) is implemented within Galerkin finite element method. The main feature of this scheme is to change the elliptic continuity equation to a hyperbolic compressible equation by introducing a new term in continuity equation named an artificial time derivative. Here, the modified Tait equation [25] of state is applied, which shows in term of density and pressure by the following relationship 
$\frac{p}{p_{0}+B}=\left(\frac{\rho}{\rho_{0}}\right)^{m}-\frac{B}{p_{0}+B}$

Where, $B$ and $m$ are constants, and $p_{0}$ and $\rho_{0}$ are reference pressure and reference density.

By using the differential, we have

$$
\frac{\partial \rho}{\partial t}=\frac{1}{\beta_{a c}} \frac{\partial p}{\partial t}
$$

where, $\beta_{a c}$ is the artificial compressibility parameter; $0<\frac{1}{\beta_{a c}}<<1$. By adding the artificial compressibility term (6) to continuity equation, we have the following equation

$\frac{1}{\beta_{a c}} \frac{\partial p}{\partial t}+\frac{\partial u_{r}}{\partial r}+\frac{1}{r} u_{r}+\frac{1}{r} \frac{\partial u_{\theta}}{\partial \theta}+\frac{\partial u_{z}}{\partial z}=0$

Now by introducing the approximations for velocity and pressure fields based on respective shape functions $\psi_{i}$ and $\phi_{j}$ ( $i=1,2, \ldots, 6$, total number of nodes including mid-side points and $j=1,2,3$, number of vertex nodes only) we gather the following matrix formulations

$\left[M_{p}\right][\dot{p}]+\left[Q_{1}^{\tau}\right]\left[u_{r}\right]+[q]\left[u_{r}\right]+\left[Q_{2}^{\tau}\right]\left[u_{\theta}\right]+\left[Q_{3}^{\tau}\right]\left[u_{z}\right]=0$,

$$
\begin{aligned}
& {[M]\left[\dot{u}_{r}\right]+\left[C\left(u_{r}, u_{\theta}, u_{z}\right)\right]\left[u_{r}\right]+\left[c_{\theta}\right]\left[u_{\theta}\right]} \\
& -\frac{1}{\operatorname{Re}}\left[Q_{1}\right][P]+\left[K_{11}\right]\left[u_{r}\right]+[k]\left[u_{r}\right]+ \\
& {\left[K_{22}\right]\left[u_{r}\right]+\left[K_{33}\right]\left[u_{r}\right]+\left[K_{12}\right]\left[u_{\theta}\right]=0}
\end{aligned}
$$

$[M]\left[\dot{u}_{\theta}\right]+\left[C\left(u_{r}, u_{\theta}, u_{z}\right)\right]\left[u_{\theta}\right]+\left[c_{r}\right]\left[u_{r}\right]$

$-\frac{1}{\operatorname{Re}}\left[Q_{2}\right][P]+\left[K_{11}\right]\left[u_{\theta}\right]+[k]\left[u_{\theta}\right]+$

$\left[K_{22}\right]\left[u_{\theta}\right]+\left[K_{33}\right]\left[u_{\theta}\right]-\left[K_{21}\right]\left[u_{r}\right]=0$

'(10)

$[M]\left[\dot{u}_{z}\right]+\left[C\left(u_{r}, u_{\theta}, u_{z}\right)\right]\left[u_{z}\right]-$

$\frac{1}{\operatorname{Re}}\left[Q_{3}\right][P]+\left[K_{11}\right]\left[u_{z}\right]+\left[K_{22}\right]\left[u_{z}\right]$

$+\left[K_{33}\right]\left[u_{z}\right]=0$.

Such that,

1. Mass Matrix,

$[M]=\int_{\Omega} e \psi \psi^{\tau} d \Omega$,

$\left[M_{p}\right]=\frac{1}{\beta_{a c}} \int_{\Omega} e \phi \phi^{\tau} d \Omega$.

2. Convective Matrix,

$\left[C\left(u_{r}, u_{\theta}, u_{z}\right)\right]=\int_{\Omega} e\left(\psi \psi^{\tau} u_{r} \frac{\partial \psi^{\tau}}{\partial r}+\right.$ $\left.\frac{1}{r} \psi \psi^{\tau} u_{\theta} \frac{\partial \psi^{\tau}}{\partial \theta}+\psi \psi^{\tau} u_{z} \frac{\partial \psi^{\tau}}{\partial z}\right) d \Omega$,

$\left[c_{\theta}\right]=-\int_{\Omega^{e}} \frac{1}{r} \psi \psi^{\tau} u_{\theta} \psi^{\tau} d \Omega$,

$\left[c_{r}\right]=\int_{\Omega^{e}} \frac{1}{r} \psi \psi^{\tau} u_{\theta} \psi^{\tau} d \Omega$.

3. Diffusive Matrix, 
where

$\left[K_{11}\right]=\frac{\beta}{\operatorname{Re}} \int_{\Omega^{e}}\left(\frac{\partial \psi}{\partial r} \frac{\partial \psi^{\tau}}{\partial r}-\frac{1}{r} \psi \frac{\partial \psi^{\tau}}{\partial r}\right) d \Omega$,

$\left[K_{22}\right]=\frac{\beta}{R e} \int_{\Omega^{e}} \frac{1}{r^{2}} \frac{\partial \psi}{\partial \theta} \frac{\partial \psi^{\tau}}{\partial \theta} d \Omega$,

$\left[K_{33}\right]=\frac{\beta}{R e} \int_{\Omega^{e}} \frac{\partial \psi}{\partial z} \frac{\partial \psi^{\tau}}{\partial z} d \Omega$,

$\left[K_{12}\right]=\left[K_{21}\right]=\frac{2 \beta}{R e} \int_{\Omega^{e}} \frac{1}{r^{2}} \psi \frac{\partial \psi^{\tau}}{\partial \theta} d \Omega$,

$[k]=\frac{\beta}{\operatorname{Re}} \int_{\Omega^{e}} \frac{1}{r^{2}} \psi \psi^{\tau} d \Omega$.

4. Gradient Matrix,

$\left[Q_{1}\right]=\int_{\Omega^{e}} \frac{\partial \psi}{\partial r} \phi^{\tau} d \Omega$

$\left[Q_{2}\right]=\int_{\Omega^{e}} \frac{1}{r} \frac{\partial \psi}{\partial \theta} \phi^{\tau} d \Omega$,

$\left[Q_{3}\right]=\int_{\Omega^{e}} \frac{\partial \psi}{\partial z} \phi^{\tau} d \Omega$,

$[q]=\int_{\Omega^{e}} \frac{1}{r} \phi \psi^{\tau} d \Omega$.

The shape functions from the theory of area coordinates will be employed as the quadratic and linear triangular shape functions for velocities and pressure, respectively. In this context, the quadratic and linear shape functions in the natural triangular area coordinates are given as

$\psi=[A][R], \quad$ (Quadratic)

$$
\phi=[I][E]=[E], \quad(\text { Linear })
$$

$[A]=\left[\begin{array}{cccccc}1 & 0 & 0 & -1 & 0 & -1 \\ 0 & 1 & 0 & -1 & -1 & 0 \\ 0 & 0 & 1 & 0 & -1 & -1 \\ 0 & 0 & 0 & 4 & 0 & 0 \\ 0 & 0 & 0 & 0 & 4 & 0 \\ 0 & 0 & 0 & 0 & 0 & 4\end{array}\right],[R]=\left[\begin{array}{c}L_{1}^{2} \\ L_{2}^{2} \\ L_{3}^{2} \\ L_{1} L_{2} \\ L_{2} L_{3} \\ L_{3} L_{1}\end{array}\right], \quad[E]=\left[\begin{array}{c}L_{1} \\ L_{2} \\ L_{3}\end{array}\right]$.

The natural triangular area coordinates $L_{1}$,

$L_{2}$ and $L_{3}$ of the cylindrical coordinates are defined as

$L_{i}=\frac{1}{2 A_{\text {area }}}\left(a_{i}+b_{i} r+c_{i} z\right), \quad(i=1,2,3)$

Where, $A_{\text {area }}$ is the area of the element's triangular and $a_{i}, b_{i}$, and $c_{i}$ are coefficients.

Thus, under these assumptions the equations

(8)-(11) can be rewritten in the matrix

formulation as

$\left[\begin{array}{cccc}M & 0 & 0 & 0 \\ 0 & M & 0 & 0 \\ 0 & 0 & M & 0 \\ 0 & 0 & 0 & M_{p}\end{array}\right]\left[\begin{array}{c}\dot{u}_{r} \\ \dot{u}_{\theta} \\ \dot{u}_{z} \\ \dot{p}\end{array}\right]+\left[\begin{array}{cccc}S_{r} & c_{\theta} & 0 & \frac{-1}{R e} Q_{1} \\ c_{r} & S_{\theta} & 0 & 0 \\ 0 & 0 & S_{z} & \frac{-1}{R e} Q_{3} \\ Q_{1}^{\tau}+q & 0 & Q_{3}^{\tau} & 0\end{array}\right]\left[\begin{array}{c}u_{r} \\ u_{\theta} \\ u_{z} \\ p\end{array}\right]=\left[\begin{array}{l}0 \\ 0 \\ 0 \\ 0\end{array}\right]$,

such that,

$\left[S_{r}\right]=\left[C_{r}\left(u_{r}\right)\right]+\left[C_{z}\left(u_{z}\right)\right]+\left[K_{11}\right]+[k]+\left[K_{33}\right]$,

$\left[S_{\theta}\right]=\left[C_{r}\left(u_{r}\right)\right]+\left[C_{z}\left(u_{z}\right)\right]+\left[K_{11}\right]+[k]+\left[K_{33}\right]$,

$\left[S_{z}\right]=\left[C_{r}\left(u_{r}\right)\right]+\left[C_{z}\left(u_{z}\right)\right]+\left[K_{11}\right]+\left[K_{33}\right]$. 
Consequentially, by using the theory of area coordinates for triangular elements, the mass and artificial compressibility matrix can be expressed as

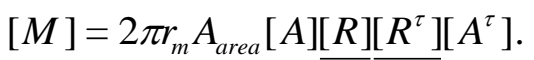

$\left[M_{p}\right]=2 \pi r_{m} A_{\text {area }} \frac{1}{\beta_{a c}}[E]\left[E^{\tau}\right]$.

Where,

$r_{m}=\frac{r_{1}+r_{2}+r_{3}}{3}, z_{m}=\frac{z_{1}+z_{2}+z_{3}}{3}$

Also the derivative form of shape function can be defined as

$$
\frac{\partial \psi}{\partial r}=[A][B][E],
$$$$
\begin{array}{r}
\text { where, }[B]=\frac{1}{2 A_{\text {area }}}\left[\begin{array}{ccc}
2 b_{1} & 0 & 0 \\
0 & 2 b_{2} & 0 \\
0 & 0 & 2 b_{3} \\
b_{2} & b_{1} & 0 \\
0 & b_{3} & b_{2} \\
b_{3} & 0 & b_{1}
\end{array}\right] \text {, } \\
{[C]=\frac{1}{2 A_{\text {area }}}\left[\begin{array}{ccc}
2 c_{1} & 0 & 0 \\
0 & 2 c_{2} & 0 \\
0 & 0 & 2 c_{3} \\
c_{2} & c_{1} & 0 \\
0 & c_{3} & c_{2} \\
c_{3} & 0 & c_{1}
\end{array}\right] .}
\end{array}
$$

In the other hand, the final diffusion matrix formula can be written as

$$
\begin{aligned}
& {\left[K_{11}\right]=2 \pi r_{m} A_{\text {area }} \frac{\beta}{\operatorname{Re}}[A][B]\left[\underline{[E]}\left[E^{\tau}\right]\left[B^{\tau}\right]\left[A^{\tau}\right]-\right.} \\
& 2 \pi A_{\text {area }} \frac{\beta}{\operatorname{Re}}[A][R]\left[E^{\tau}\right]\left[B^{\tau}\right]\left[A^{\tau}\right],
\end{aligned}
$$

$$
\left[K_{33}\right]=2 \pi r_{m} A_{\text {area }} \frac{\beta}{\operatorname{Re}}[A][C]\left[\underline{[E]}\left[E^{\tau}\right]\left[C^{\tau}\right]\left[A^{\tau}\right],\right.
$$

$$
[k]=2 \pi A_{\text {area }} \frac{\beta}{r_{m} \operatorname{Re}}[A] \underline{[R]}\left[R^{\tau}\right]\left[A^{\tau}\right] .
$$

Moreover, the gradient matrix is defined as

$$
\left[Q_{1}\right]=2 \pi r_{m} A_{\text {area }}[A][B] \underline{[E]} \underline{\left[E^{\tau}\right]},
$$

$\left[Q_{3}\right]=2 \pi r_{m} A_{\text {area }}[A][C][E]\left[E^{\tau}\right]$,

$[q]=2 \pi A_{\text {area }}\left[\underline{E]}\left[\underline{\left.R^{\tau}\right]}\left[A^{\tau}\right]\right.\right.$.

Finally, the convective matrix is given by

$\left[C_{r}\left(u_{r}\right)\right]=2 \pi r_{m} A_{\text {area }}[A][R]\left[R^{\tau}\right]\left[A^{\tau}\right]\left[u_{r}\right]$

$\left[E^{\tau}\right]\left[B^{\tau}\right]\left[A^{\tau}\right]$,

$\left[C_{z}\left(u_{z}\right)\right]=2 \pi r_{m} A_{\text {area }}[A][R]\left[R^{\tau}\right]\left[A^{\tau}\right]\left[u_{z}\right]$

$\left[E^{\tau}\right]\left[C^{\tau}\right]\left[A^{\tau}\right]$, 


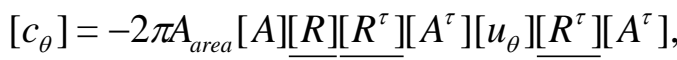
(30)

$\left[c_{r}\right]=2 \pi A_{\text {area }}[A][R]\left[R^{\tau}\right]\left[A^{\tau}\right]\left[u_{\theta}\right]\left[R^{\tau}\right]\left[A^{\tau}\right]$. (31)

\section{Problem specification}

In the present study, Poiseuille flow along a $2 D$ axisymmetric straight channel, under isothermal condition is investigated. For this purpose, a structured, uniform, quadrilateralbased, triangular finite element mesh is utilized, for the $2 \times 2$ mesh as illustrated in Fig. 1, with mesh characteristics are introduced in Table 1.

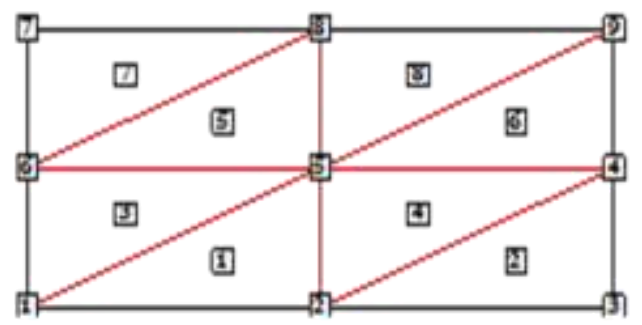

Fig.1: Structured $2 \times 2$ finite element mesh.

\begin{tabular}{|c|c|c|c|c|}
\hline Mesh & Total & Total & Boundary & Pressure \\
& Element & Nodes & Nodes & Nodes \\
\hline $2 \times 2$ & 8 & 25 & 16 & 9 \\
\hline
\end{tabular}

Table 1: Mesh characteristic parameters
Boundary conditions $(B C s)$ : The setting of $B C$ s of the present channel problem is laid as follows (see Fig.2):

(a) Poiseuille(Ps) flow is specified at the inlet (AD) with $u_{z}=4 r(1-r)$.

(b) No-slip $B C s$ is applied on the channel walls $(A B)$ and $(C D)$.

(c) Along the outflow boundary $(B C s)$, zero radial velocity applies.

$$
u_{r}=u_{z}=0
$$

(Top wall)

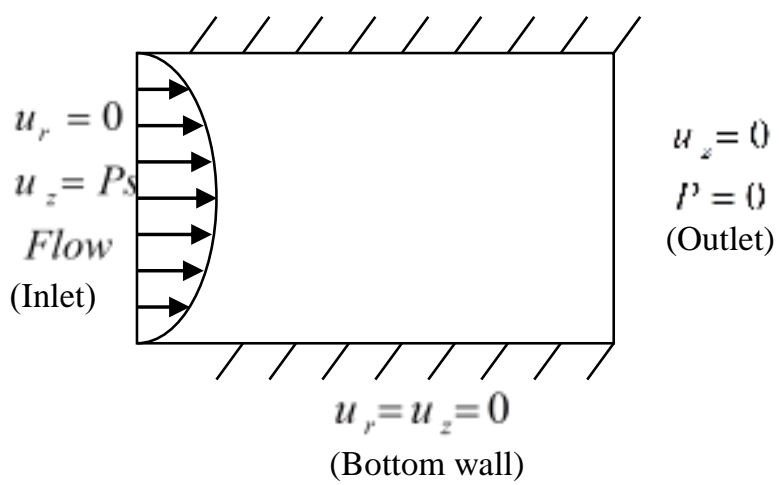

Fig. 2: Schema for flow problem, boundary conditions.

\section{Exact solutions of Naiver-Stokes}

\section{equations for parallel flow}

Finding exact solution of Naiver-Stokes equations, displays mathematical difficulties because of the nonlinear terms of equations. However, some time the analytical solutions can be found in specific cases. Firstly, to find the analytic solution, the system of differential equations for incompressible flow can be reexpressed as. 
Continuity equation

$$
\nabla . u=0 .
$$

Momentum equation

$$
\frac{\partial u_{r}}{\partial t}+(\bar{u} . \nabla) u_{r}=-\frac{1}{\rho} \frac{\partial p}{\partial r}+\frac{\mu_{s}}{\rho}\left(\nabla^{2} u_{r}\right) .
$$

$\frac{\partial u_{\theta}}{\partial t}+(\bar{u} . \nabla) u_{\theta}=-\frac{1}{\rho} \frac{\partial p}{\partial \theta}+\frac{\mu_{s}}{\rho}\left(\nabla^{2} u_{\theta}\right)$.

$$
\frac{\partial u_{z}}{\partial t}+(\bar{u} \cdot \nabla) u_{z}=-\frac{1}{\rho} \frac{\partial p}{\partial z}+\frac{\mu_{s}}{\rho}\left(\nabla^{2} u_{z}\right)
$$

In the case of the axisymmetric flow with vanish tangential and radial velocities $\left(u_{r}=u_{\theta}=0\right)$ and $\quad \frac{\partial p}{\partial r}=0, \frac{\partial p}{\partial \theta}=0$.

Thus, under these assumptions the continuity equation, we have

$$
\frac{\partial u_{z}}{\partial z}=0
$$

Considering a steady flow we get from the axial component of the Navier-Stokes equations

$$
\begin{aligned}
& (\bar{u} \cdot \nabla) u_{z}=u_{z} \frac{\partial u_{z}}{\partial z} . \\
& u_{z} \frac{\partial u_{z}}{\partial z}=-\frac{1}{\rho} p+\frac{\mu_{s}}{\rho} \nabla^{2} u_{z} .
\end{aligned}
$$

Where, under a constant pressure gradient

$P=-\frac{\partial p}{\partial z}$. Thus,

$$
\nabla^{2} u_{z}=\frac{1}{r} \frac{\partial}{\partial r}\left(r \frac{\partial u_{z}}{\partial r}\right)=-\frac{P}{M} ;\left(M=\frac{1}{\mu_{s} \rho}\right)
$$

By integrating, we have the general solution as

$$
u_{z}=-\frac{p}{4 M} r^{2}+c_{1} \ln (r)+c_{2}
$$

By impossing the boundary conditions $u_{z}=0$

for $r= \pm h$, we have

$u_{z}=\frac{P}{4 M}\left(h^{2}-r^{2}\right)$.

$u_{\max }$ at the center of the channel, when $r=0$ into equation (36)

$u_{\max }=\frac{P h^{2}}{4 M}$.

Thus, the analytic solution is,

$u_{\text {exact }}=\frac{u_{z}}{u_{\max }}$.

$u_{\text {exact }}=1-\left(\frac{r}{h}\right)^{2}$. 
The comparison in axial velocity between the analytic solution and numerical results is illustrated in Fig. (3) for $\beta_{a c}=100$ and $R e=1,5$. Here, the velocity profile is plotted in the fully development region of the channel. From the comparative one can observe that, the numerical results, which are appeared are reasonable compared to the exact solution, which reflects the efficiency of the numerical method that used.

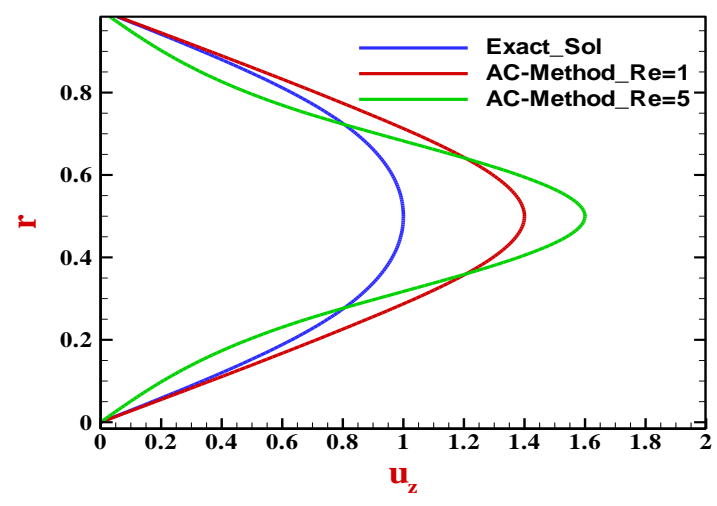

Fig. 3: Axial velocity profiles: compare between analytic and numerical solutions .

\section{Simulation results}

The fields of axial velocity $u_{z}$, according to various $R e$ at fixed $\beta_{a c}=100$ are displayed in Fig.(4). The results reveal that, the maximum level of velocity is appeared in the middle of the geometry. Here, one can observe clearly the effect of the Reynolds number on the level of $R e$, where the level of velocity is increased as $R e$ increases; rising from 1.4 when $R e=1$ to around 2 when $R e=7$. Here, the critical level of $R e$ is 7 , where the results are become diverge for the value of Re greater than 7 (see Fig.4e).

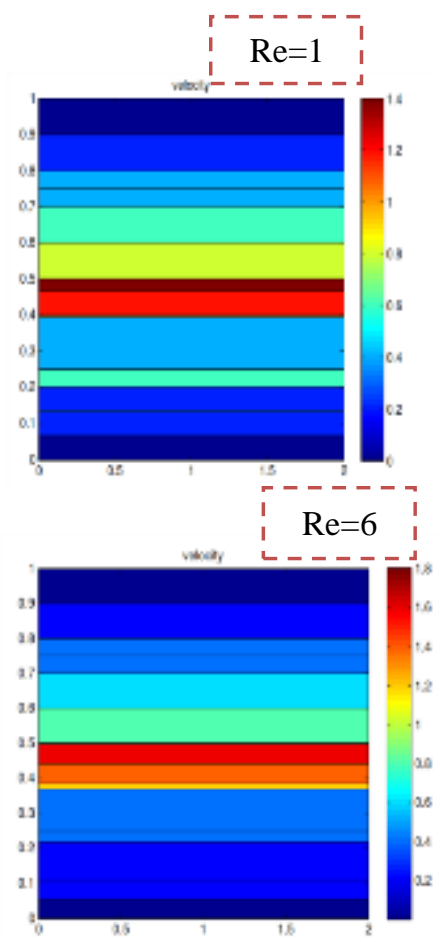

(c)

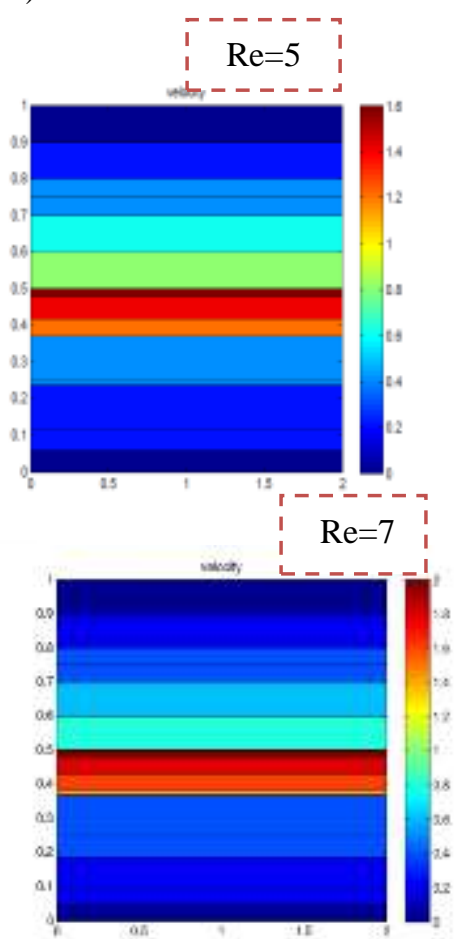

(d)

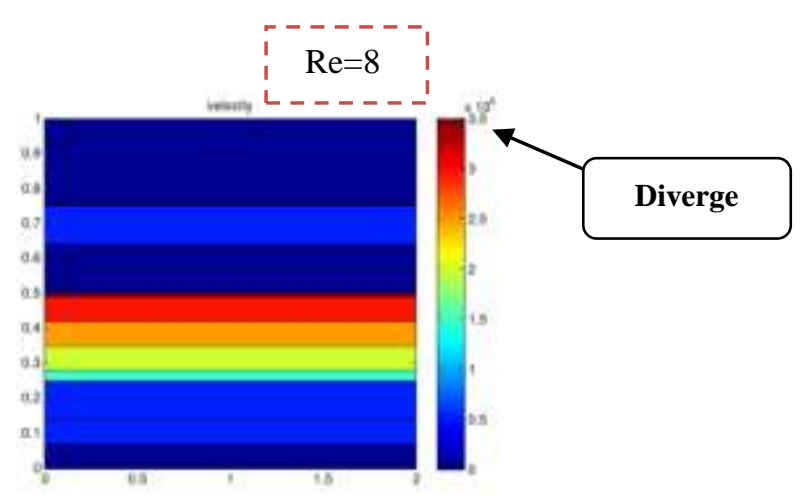

(e)

Fig. 4: Fields of axial velocity, $R e$-various, $\beta_{a c}=100$. 
The rate of convergence for pressure and axial velocity components are illustrated in Fig. (5) for different values of the artificial compressibility parameter $\left(\beta_{a c}=60,80,100\right)$ and fixed $R e=1$. Generally, the level of convergence for velocity component is high compared to pressure because of the influence of nonlinearity behaviour. In addition and as anticipated the findings show that, the rate of convergence is increased as the values of $\beta_{a c}$ are decreased due to the compressibility effects.

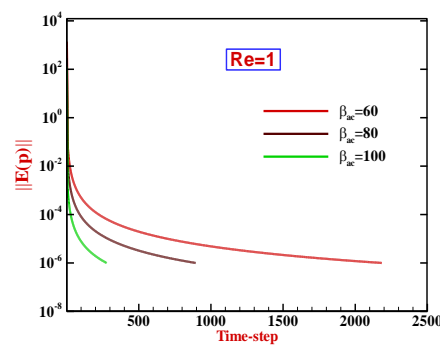

(a)

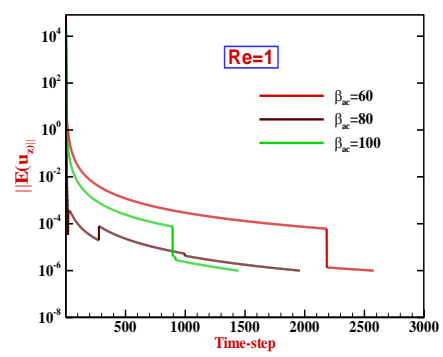

(b)
Fig. 5: Convergence of pressure and velocity components,

$$
\beta_{c c} \text {-various, } \operatorname{Re}=1
$$

Obviously, when the Reynolds number is increased, the velocity gradients will be developed which reflects the difficulties of convergence for large Re number. Thus, we have directed our interest in the discussing and studying the effects and levels of Reynolds number. Fig.(6) shows that the convergence of axial velocity for different levels of $R e$ and fixed $\beta_{a c}=100$. From the Figure one can see that the level of time increments increases exponentially, whenever you get increased in $R e$. For example when $R e=0.01$, the level of time steps is much less than that in $R e=6$ (see Fig. (6a) and (6e)), so the level of convergence of velocity is faster when $R e$ is small. We note also that for the critical value of $R e=7$ as shown in the Fig.(6f) we found it is so difficult to reach the convergence (needed around 150000 time-step).

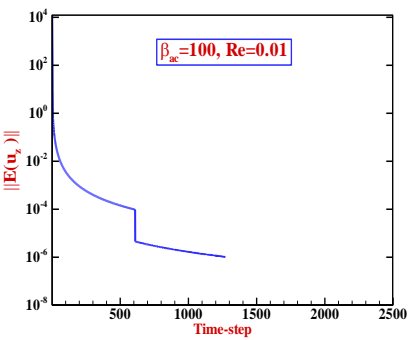

(a)

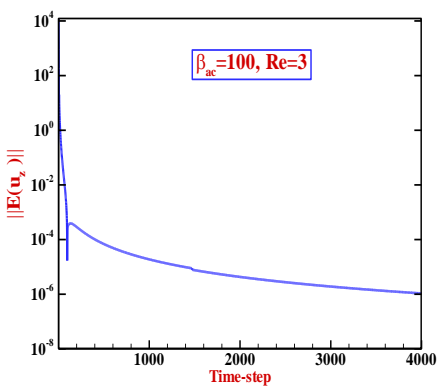

(c)

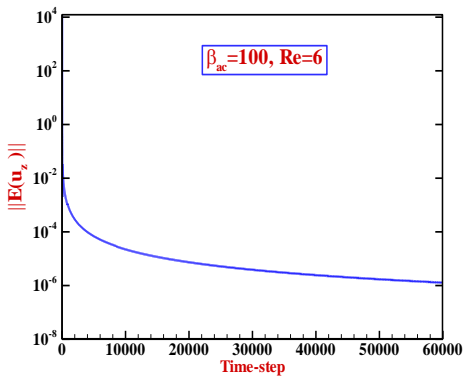

(e)

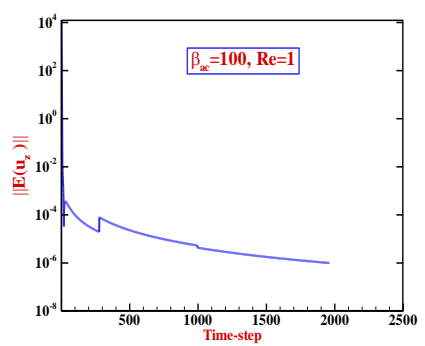

(b)

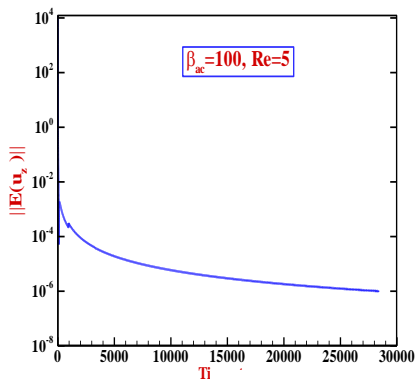

(d)

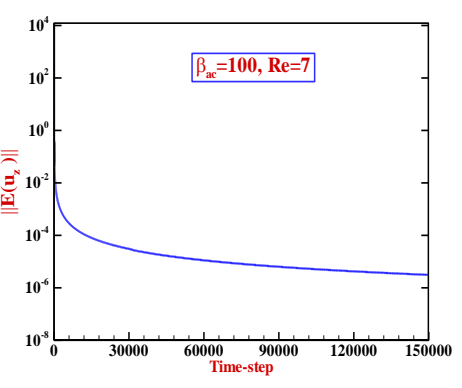

(f)
Fig. 6: Velocity convergence, $\beta_{a c}=100, R e$ variation. 


\section{Summary}

In this study, the method of artificial compressibility within the finite element method is presented as an effective way to solve the Navier-Stokes equations in cylindrical coordinates system. The analysis of finite element method for the equations under considerations has been conducted.

Here, under special case the analytic solution of these equations is obtained to give as opportunity to compare the numerical result and have clear feature of the method. The convergence analysis of velocity and pressure was done to identify the effect of $\operatorname{Re}$ and $\beta_{a c}$ on the acceleration of convergence. From the results one can observe that, the rate of convergence is reduc ${ }^{n}{ }^{n} e$ reduced, while the rate of convergence is reduced as $\beta_{a c}$ increased.

\section{References}

1. A.J. Chorin, A numerical method for solving incompressible viscous flow problems, J.

Comput. Phys. 2, 12-26 (1967).

2. J.L. Steger, P. Kutler, Implicit finitedifference procedures for the computation of vortex wakes, AIAA J. 15, 581-590 (1977).

3. R. Peyret, T.D. Taylor, Computational Methods for Fluid Flow, Springer-Verlag Inc., New York, 358 (1983).

4. J.L. Chang, D. Kwak, On the method of pseudo-compressibility for numerically solving incompressible flows, AIAA Pap., 840252 (1984).

5. D. Choi, C.L. Merkle, Application of time-iterative schemes to incompressible flow, AIAA

$$
\text { J. 23, 1518-1524 (1985). }
$$

6. A. Rizzi, L.-E. Eriksson, Computation of inviscid incompressible flow with rotation, $\mathrm{J}$.

Fluid Mech. 153, 275-312 (1985). 
7. S.E. Rogers, D. Kwak, C. Kiris, Steady and unsteady solutions of the incompressible

Navier-Stokes equations, AIAA Journal,29(4), 603-610 (1991).

8. R. Temam, Navier-Stokes Equations, North-Holland, 426-430 (1979).

9. R. Peyret, Unsteady evolution of a horizontal jet in a stratified fluid, J. Fluid Mech. 28, 49-63 (1976).

10. C.L. Merkle, M. Athavale, Timeaccurate unsteady incompressible flow algorithms based on artificial compressibility, AIAA J. 87, 1137-1147 (1987).

11. B.V. Rathish Kumar, T. Yamaguchi, H. Liu,R. Himeno, A parallel 3D unsteady incompressible flow solver on VPP700, Parallel Comput. 27, 1687-1713 (2001).

12. W.Y. Soh, J.W. Goodrich, Unsteady solution of incompressible Navier-Stokes equations, J. Comput. Phys. 79, 113-134 (1988).
13. P.R. McHugh, J.D. Ramshaw, Damped artificial compressibility iteration scheme for

$$
\text { implicit calculations of unsteady }
$$
incompressible flow, Int. J. Numer. Methods Fluids 19, 439-455 (1995).

14. C. de Joue“tte, O. Laget,J.-M. Le Gouez, H. Viviand, A dual time stepping method for

fluid- structure interaction problems, Comput. Fluids 31, 509-537 (2002).

15. D. Mateescu, M.P. Païdoussis, F. Be'langer, A time-integration method using artificial compressibility for unsteady viscous flows, J. Sound Vib. 177 (2), 197-205 (1994).

16. R.M. Gatiganti, K.J. Badcock, F. Cantariti, L. Dubuc, M. Woodgate, B.E. Richards,

Evaluation of an unfactored method for the solution of the incompressible flow equations using artificial compressibility, Appl. Ocean Res. 20, 179-187 (1998). 
17. M. Rosenfeld, D. Kwak, M. Vinokur, A Solution Method for Unsteady, Incompressible

Navier-Stokes Equations in Generalized Curvilinear Coordinate Systems, J. Comp. Phys.

Vol 94, 102-137 (1991).

18. S.E. Rogers, D. Kwak, U. Kaul, On the accuracy of the pseudocompressibility method in solving the incompressible Navier Stokes equations, Appl. Math. Model. 11, 35-44 (1987).

19. P.A. Madsen, J. Larsen, An efficient finite-difference approach to the mildslope equation, Coast. Eng. 11, 329-351 (1987).

20. J. Farmer, L. Martinelli, A. Jameson, Fast multigrid method for solving incompressible hydrodynamic problems with free surfaces, AIAA Journal, Vol. 32, 11751182 (1994).
21. L. Yuan, Comparison of implicit multigrid schemes for three-dimensional incompressible

flows, J. Comput. Phys., Vol. 177, 134155 (2002).

22. F. Bassi, S. Rebay, High-order accurate discontinuous finite element solution of the $2 D$

euler equations, Journal of Computational Physics, Vol. 138, 251-285 (1997).

23. A. Al-Muslimawi, Numerical analysis of partial differential equations for viscoelastic and free surface flows, Phd thesis,University of Swansea (2013).

24. A. Al-Muslimawi, H.R. TamaddonJahromi, M.F. Webster, Numerical simulation of tube tooling cable-coating with polymer melts, The 13th International Symposium on Applied

Rheology(ISAR), The Korean Society of Rheology, 31-55 (2013).

25. P.G. Tait, HMSO, London 2(4), (1888). 
التحليل العددي للتدفق النيوتوني على أساس طريقة الانضغاط الاصطناعي (AC)

$$
\begin{aligned}
& \text { بثائر كاظم جاسم علاء حسن عبل الله } \\
& \text { قسم الرياضيات, كلية العلوم , جامعة البصرة }
\end{aligned}
$$

في هذه الدراسة التحليل العددي لمعادلة التدفق النيوتوني غبر القابل للانضغاط تم تتاوله باستعمال طريقة الأنضغاط الأصطناعي (AC) بالاعتماد على طريقة كالركن للعناصر المحددة. كما هو معلوم معادلات نافييهستوكس توظف دائما لوصف حركة الموائع. ان هذه النموذج و الذي يتكون بالأساس من معادلتين تفاضليتين هما معادلة حفظ الكتلة وحفظ الزخم تم دراسته في نظام الإحداثيات الاسطوانية (Axisymmetric flow). تأثير بعض العو امل مثل عدد رينولدز (Re) ومعامل الانضغاط الاصطناعي (مac) قد نوقش في هذه الدر اسة. بصورة اساسية هذه الدراسة ركزت على تأثثر هذه العوامل على معدل التقارب للحلول العددية. لتأكيد تحليل الطريقة تم استخدام تدفق بوازول (Poiseuille flow) داخل قناة دائرية كاختبار بسيط للطريقة من خلال أخذ مقطع عرضي دائري. 